\title{
St John's wort was no better than placebo for reducing depression scores
}

\author{
Shelton RC, Keller MB, Gelenberg A, et al. Effectiveness of St John's wort in major depression. A randomized controlled \\ trial.JAMA 2001 Apr 18;285:1978-86.

\section{QUESTION: In patients with major depression, is St John's wort (Hypericum extract) better than placebo for reducing depressive symptoms?}

\section{Design}

Randomised (allocation concealed*), blinded \{clinicians, patients, outcome assessors, and statisticians $\} \nmid$, placebo controlled trial with 8 weeks of follow up.

\section{Setting}

11 academic medical centres in the USA.

\section{Patients}

200 physically healthy outpatients who were $\geqslant 18$ years of age (mean age 42.4 y, $64 \%$ women); had major depression (single episode or recurrent) without psychotic features according to the Diagnostic and Statistical Manual of Mental Disorders, Fourth Edition for $\geqslant 4$ weeks; and scored $\geqslant 20$ on the Hamilton Depression Rating Scale (HDRS). Exclusion criteria included having cognitive, post-traumatic stress, eating, or substance use disorders in the previous 6 months; panic disorder in the previous year; and bipolar, psychotic, or primary personality disorders. Patients who improved during the 1 week placebo run-in period were also excluded. $84 \%$ of patients completed the study.

\section{Intervention}

Patients were allocated to St John's wort, $1300 \mathrm{mg}$ tablet 3 times daily $(n=98)$, or to placebo $(n=102)$ for 8 weeks. The dose was increased to 4 tablets $(1200 \mathrm{mg})$ daily for those who had not sufficiently improved by week 4 (mean daily dose 3.7 tablets [1110 mg] for St John's wort, 3.6 tablets for placebo).

\section{Main outcome measures}

Rate of change in HDRS scores. Secondary outcomes included response rate (HDRS score $\leqslant 15$ and Clinical Global Impression-Improvement [CGI-I] score of 1 or 2).

\section{Main results}

Analysis was by intention to treat. A random coefficient regression model showed that both groups improved over time ( $p<0.001)$, but the groups did not differ for change in HDRS scores or response rates (table). At 8 weeks, the mean HDRS score was 14.2 for St John's wort and 14.9 for placebo ( $\mathrm{p}>0.2)$.

\section{Conclusion}

In patients with major depression, St John's wort did not improve depression scores at 8 weeks.

*See glossary.

$\dagger$ Information provided by author.

\section{COMMENTARY}

The context for the study by Shelton $e t$ al is the Cochrane review by Linde and Mulrow showing that St John's wort extract is efficacious. ${ }^{1}$ The study by Shelton et al is rigorous and meets every reasonable expectation for a wellconducted pharmaceutical study. Although the result was negative, many will see this as the "gold standard" study, carrying far more qualitative weight than many studies cited in Linde and Mulrow. ${ }^{1}$

However, it is not quite the ace of studies. The absolute test for inefficacy of an agent is a 3-arm study in which a new agent, placebo, and reference agent of known efficacy are compared. If the reference agent differs from placebo, but the new agent does not, then this finding provides maximal evidence that the new agent does not work. If neither reference nor new agent differs from placebo then the study has produced an unlucky result-and an uninformative one. Shelton et al cannot be reproached for not running a 3-arm study because, given the conclusions of Linde $e t a l{ }^{2}$ this trial could have been expected to be a confirmatory study.

The confusion surrounding St John's wort leaves clinicians in an "anything goes" situation. Enough positive data exist that it would be reasonable for a clinician to recommend St John's wort, or, as is often the case, to acquiesce to patients' wishes. Alternatively, sufficient uncertainty exists that it would be equally reasonable for the clinician not to engage in explicit or implicit endorsements of St John's wort.

Many patients are going to request St John's wort or selfadminister it with or without the clinician's approval. Anecdotally, co-administration of St John's wort with prescribed antidepressants is common. Thus, it seems reasonable that treating clinicians should have at least a familiarity with the pharmacology and safety data regarding St John's wort analogous to having a working knowledge of the effects of, say, alcohol or nicotine.

Unravelling the uncertainties surrounding St John's wort will take years to achieve. Meanwhile, we should remember that prescribed antidepressants have efficacy, tolerability, and safety data.

Chris Hawley, MB, BS

Tim Gale, $\mathrm{PhD}$

University of Hertfordshire

Hertfordshire, UK

1 Linde K, Mulrow CD. St John's wort for depression. Cochrane Database Syst Rev 2001;(2):CD000448.

2 Linde K, Ramirez G, Mulrow CD, et al. St John's wort for depression-an overview and meta-analysis of randomised clinical trials. BMJ 1996;313:253-8.
Sources of funding: Pfizer Inc. and National Institute of Mental Health.

For correspondence: Dr $R$ C Shelton, 1500 21st Avenue South, Suite 2200, Nashville, TN 37212, USA. Fax +16153439038 .

Abstract and commentary also appear in Evidence-Based Mental Health. 